\title{
UNA PANDEMIA MÁS: LA VIOLENCIA DE GÉNERO EN EL MARCO DE LOS FEMINISMOS MEXICANOS
}

\section{ONE MORE PANDEMIC:}

GENDER VIOLENCE WITHIN THE FRAMEWORK OF MEXICAN FEMINISMS

\author{
Ana Lau Jaiven \\ iD orcid.org/0000-0002-5389-8817 \\ Universidad Autónoma Metropolitana-Xochimilco \\ México \\ lauanaj15@gmail.com
}

\begin{abstract}
By reviewing articles in the press, texts on violence against women and my own experience, this research explains the actions and discursive practices of generations of Mexican feminists over time. For this reason, the link established between the feminisms of the seventies and the young feminists of the twenty-first century and the way in which they combat gender-based violence is analyzed. The objective is to establish a chronological cartography of how the actions that have led to feminist practices have been represented.
\end{abstract}

Keywords: femicides, feminist actions, violence.

\section{Resumen}

Mediante la revisión de artículos de la prensa, textos sobre violencia contra las mujeres y mi propia experiencia, esta investigación da cuenta de las acciones y prácticas discursivas de las dos generaciones de feministas mexicanas a lo largo del tiempo; por ello se analiza el vínculo que se establece entre los feminismos de los años 70 y las jóvenes feministas del siglo XXI y de la manera en que combaten las violencias en razón de género. El objetivo es establecer una cartografía cronológica de cómo se han ido representando esas acciones que han desembocado en las prácticas feministas.

Palabras clave: acciones feministas, feminicidios, violencias. 
\#Yo no me muero, me matan

Las mujeres se están rebelando Los hombres no saben qué hacer Todas las flechas en movimiento Las reglas se vuelven a hacer "Mujeres", de Julieta Venegas

\section{La historia reciente: un acercamiento a la violencia}

Cómo acercarme a la violencia de género en tanto manifestación extrema de la desigualdad y maltrato impuesto por relaciones tóxicas de poder ${ }^{1}$ de los hombres hacia las mujeres. Cuestión compleja para una historiadora acostumbrada a los hechos y acontecimientos históricos del pasado, en un tema, lugar concreto y espacio de tiempo. El asunto que estoy por abordar y la temporalidad que he elegido de 2000 a 2021 marcan un punto de inflexión y de cambio no sólo en lo que se refiere a la historia reciente, sino de la manera en que voy a aproximarme a esa temática compleja, desconcertante, confusa y multidimensional, que adopta una diversidad de miradas que pueden ser al mismo tiempo debatidas y/o examinadas. Además, no hay una respuesta única que alcance a explicar y aclarar los asesinatos de mujeres por ser mujeres en razón de género y la omisión investigativa de las autoridades que han empujado a que sean los y las familiares quienes busquen datos y pruebas que se necesitan para que el asesinato de una mujer sea resuelto y reclasificado como feminicidio.

Este ensayo es un acercamiento de investigación empírica apoyada en recortes de la prensa que he recolectado a lo largo de tres años y que me han permitido seguir los acontecimientos que relato. Asimismo, he consultado textos y artículos sobre la temática. Los textos que mencionan a las feministas de la segunda ola y a las jóvenes morras de la tercera ola y a sus movimientos apenas están apareciendo, ya que

1 Como relaciones tóxicas quiero decir rasgos masculinos exagerados que muchas culturas han aceptado - glorificado en los hombres y que se aceptan como conflictos en sus roles de género. es muy pronto para examinar sus particularidades. En este sentido, quienes más ha escrito sobre algunas de esas acciones son sociólogas como Daniela Cerva Cerna (2020), Emanuela Borzacchiello (2020), Guiomar Rovira-Sancho (2013) y Kenia Salas (2020). Las cuatro que menciono han Ilevado a cabo entrevistas con las jóvenes y al igual que yo han participado en las marchas como feministas realizando trabajo de campo.

Este ensayo se respalda en la coexistencia entre la feminista académica que soy, las investigaciones que realizo y las sujetas y prácticas de los feminismos que investigo. Para escribir este ensayo me apoyo en lo que Donna Haraway (1991) considera como conocimiento situado, definido como el lugar desde el cual se habla; ningún conocimiento está desvinculado de su contexto ni de la subjetividad de quien lo emite. Todo conocimiento se produce en situaciones históricas y sociales particulares, por mucho que se quiera hacer aparecer el verdadero conocimiento científico como universal, neutral y por lo tanto desprovisto de relaciones directas con determinados factores políticos, culturales y sociales.

Me adentré en el tema de los feminicidios a principios del nuevo milenio, alrededor de 2001, cuando impartí docencia en la Universidad Autónoma de Ciudad Juárez y compartí conocimientos con las hoy doctoras Julia Monárrez Fragoso y Rosalba Robles Ortega, entre otras alumnas. Ellas investigaban sobre la violencia y los feminicidios; por ello, además de las discusiones sobre el tema, me llevaron a conocer los espacios inhóspitos donde habían asesinado a las mujeres en la ciudad: Lomas de Poleo, el Lote Bravo y el Campo Algodonero. El impacto que me causó contemplar en persona esos parajes e imaginarme la violencia y tortura que esas jóvenes habían sufrido antes de ser tiradas ahí, me instó a leer a profundidad los textos que empezaban a publicarse y me interesé en lo que se suponía estaba haciendo el gobierno para encontrar a los agresores y dejar de victimizar a las entonces clasificadas como "muertas de Juárez" (González Rodríguez, 2002). Ya para entonces se 
usaba la palabra feminicidios y Monárrez Fragoso los denominó "Feminicidios sexuales sistémicos" (2009). Con ella lo recuerdo bien discutía yo que no sólo en Juárez estaban sucediendo estos asesinatos de mujeres, sino que iban a irradiar a otras partes del país y hoy mi hipótesis, muy básica, desafortunadamente me ha dado la razón.

Acorde con lo mencionado, el objetivo de este ensayo reside en vincular las acciones colectivas que el movimiento feminista de la segunda ola mexicana apoyó a fin de visibilizar las violencias sexuales misóginas ${ }^{2}$ en su modalidad de feminicidios en tanto problema social y que desde entonces ha pugnado e incidido en varias instancias a fin de procurar erradicar dichas violencias. Si bien no es mi intención mapear todos los esfuerzos realizados durante las décadas de los 80 y 90 , me he de concentrar en algunos que considero han tenido mayores incidencias. Además, como se observa en el título, considero que la epidemia SARS-CoV-2 y los feminicidios se equiparan, ya que ambos son una pandemia que atraviesa de manera interseccional (Viveros Vigoya, 2016) los asesinatos de mujeres. Desde finales de 2018 se empezó a hablar de una enfermedad aparecida en la provincia de Wuhan, China. No se sabía qué era ni cómo se combatía. Para 2019 ese virus empezó a desplazarse a otros países del planeta y la Organización Mundial de la Salud (OMS) inició investigaciones para regularlo. Se confinó en los hogares a la mayoría del mundo, sin lograr erradicarlo. Los grandes laboratorios internacionales, que ya venían investigando ciertos tipos de virus, se aplicaron a sacar vacunas que protegieran a la población. No

\footnotetext{
2 La misoginia es definida por Marcela Lagarde (2012) como la creencia en la inferioridad de las mujeres en comparación con los hombres, y como consecuencia de ello se utiliza, agrede y se somete a las mujeres, haciendo uso de la legitimidad patriarcal. La misoginia es certera cuando ni siquiera nos preguntamos si la dominación genérica de las mujeres es injusta, dañina y éticamente reprobable. Está presente cuando se piensa y actúa como si fuese natural que se dañe, se margine, se maltrate y se promuevan acciones y formas de comportamiento hostiles, agresivas y machistas hacia las mujeres y sus obras, y hacia lo femenino; es, en definitiva, un recurso de poder que justifica la opresión a las mujeres.
}

obstante, la mortalidad alcanzó niveles muy altos. Hoy día el virus SARS-CoV-2 ha mutado de diferentes maneras y parece haberse instalado en la sociedad humana por un largo periodo.

Esta introducción me permite hablar de violencias. Ese confinamiento que mencioné llevó a la violencia en los hogares, que de por sí ya acusaba altas cifras. La violencia tiene una historia y ella inicia por razones de espacio, desde la década de los años 70 con la irrupción de la Segunda Ola del movimiento feminista mexicano.

Esos grupos feministas de los años 70, 80 y 90 pusieron el foco de sus acciones en la despenalización del aborto, el derecho al cuerpo, el salario en igualdad de condiciones y también en el establecimiento de penas ante casos de violación, hostigamiento, maltrato y golpes dentro del hogar y fuera de él; consiguieron reformar algunas leyes para volverlas más rigurosas y así castigar a los agresores. Asimismo, hubo quienes se acercaron a las víctimas para brindarles atención psicológica y legal (Lau Jaiven, 2002). Desde 1975, la feminista norteamericana Kate Millet (1975: 58) interpretaba la violencia contra las mujeres como violencia estructural sobre el colectivo femenino. Monserrat Sagot, socióloga costarricense, por su parte afirma que la violencia contra las mujeres se identifica como un problema social endémico, producto de una organización social estructurada sobre la base de la desigualdad de género (Sagot Rodríguez, 2021).

Dicho lo anterior, es posible argumentar lo poco que preocupaba a gobiernos e instituciones la violencia hacia las mujeres. En 1975, México fue sede de la Primera Conferencia Internacional sobre la Mujer, propuesta por la Organización de las Naciones Unidas (ONU). El movimiento feminista a nivel internacional boicoteó la Conferencia y por lo tanto no aceptó participar; sin embargo, algunas de sus integrantes lo hicieron de manera independiente, de la misma manera que algunas organizaciones no gubernamentales, recién creadas. Durante la Conferencia se demandó reconocer, entre 
otras cuestiones, a la violencia como un problema medular para las mujeres. No hubo respuesta ni de los gobiernos ni de Naciones Unidas, ya que entonces se consideraba que la violencia era una problemática del ámbito privado y por ello no había que entrometerse. A partir de reuniones, coaliciones y redes las feministas mexicanas se concentraron desde entonces en la resolución de tres ejes: la despenalización del aborto, ${ }^{3}$ la lucha contra la violación y la protección a las mujeres golpeadas. Como es posible observar, la violencia tenía otras modalidades que poco a poco fueron cambiando de acuerdo con las maneras de ejercerla.

En la década siguiente las mujeres feministas siguieron insistiendo en que se tomaran en cuenta las violencias. Los gobiernos, de acuerdo con las Conferencias internacionales de la Mujer, tuvieron que verse inclinados a incorporar los derechos de las mujeres en convenios internacionales, tipificando pautas de identificación, atención y eliminación de la inequidad de género. Por ejemplo, con la firma de México el 23 de marzo de 1981 del Protocolo de la CEDAW ${ }^{4}$ que urge a los Estados firmantes a cumplirlo, "se obliga a adoptar medidas urgentes para prevenir las muertes violentas, los homicidios y las desapariciones forzadas de mujeres" (CEDAW, 1979).

Otra acción muy importante, llevada a cabo en 1994, fue la emprendida por la Comisión Interamericana de Mujeres (CIM), perteneciente a la OEA, que definió la violencia esta vez de género como una violación a los derechos humanos de las mujeres. La Convención Interamericana para Prevenir, Sancionar y Erradicar la Violencia contra la Mujer, mejor conocida como Convención de Belem do Pará, estableció entre sus objetivos eliminar la violencia como condición indispensable para el desarrollo individual

3 La despenalización fue posible debido al esfuerzo y lucha de las feministas. Hoy se ha conseguido en la Ciudad de México (2007), en Oaxaca (2020) y en Hidalgo, Baja California, Colima, Coahuila y Veracruz en 2021.

4 Comité para la Eliminación de todas las Formas de Discriminación contra la Mujer (CEDAW, por sus siglas en inglés). de las mujeres (Secretaría de Relaciones Exteriores, 2008).

La violencia se convirtió en un dolor de cabeza para el gobierno y las entidades de la república. Los esfuerzos se encaminaron a intentar eliminarla, aunque sin éxito. Siguió creciendo y constantemente aparecían cuerpos asesinados y desechados en los lugares más inhóspitos de las calles.

\section{\#Disculpe usted la molestia, pero nos están matando}

En el nuevo milenio los feminicidios siguieron aumentando y las feministas denunciaron la magnitud del problema. Entre las distintas vertientes que componen el movimiento feminista los debates se incrementaron y no hubo concordancias en las maneras de actuar. Unas hablaban de la inclusión de la violencia como una cuestión de salud pública para que el Estado se encargara del problema. Las feministas no tomaron en cuenta que había que desenmascarar al patriarcado como afirma Rita Segato (2007) en tanto institución que se sustenta en el control del cuerpo y la capacidad punitiva sobre las mujeres. ${ }^{5}$

Hay que subrayar que con el apoyo de feministas y diputadas, en 2007 se consiguió promulgar la Ley General de Acceso de las Mujeres a una Vida Libre de Violencia (LGAMVLV), en cuyo artículo cuarto establece que

los principios rectores para el acceso de todas las mujeres a una vida libre de violencia que deberán ser observados en la elaboración y ejecución de las políticas públicas federales y locales son:

I. La igualdad jurídica entre la mujer y el hombre;

II. El respeto a la dignidad humana de las mujeres:

III. La no discriminación, y

IV. La libertad de las mujeres (DOF, 2015).

5 En este sentido se encuentran el machismo tóxico, las drogas, el alcohol, el desempleo, los celos y el sentido de que el cuerpo de las mujeres es de otros y se puede usar al gusto (Segato, 2007: 37). 
Esta ley se ha reformado varias veces, aumentando penas e incorporando las Alertas de Violencia de Género (AVG) como acciones gubernamentales de emergencia para enfrentar y erradicar esa violencia feminicida en un territorio determinado. Actualmente se han declarado estas Alertas de Violencia de Género (AVGM) en 19 entidades del país. La última en decretarse fue en la Ciudad de México el 21 de noviembre de 2020, debido al creciente número de feminicidios en la capital. Desafortunadamente la existencia de la ley y de las Alertas no han dado los resultados esperados. Si bien podemos aducir su existencia, pareciera que con ella o sin ella las cosas van igual, pero al menos contamos con una ley a la cual referirnos en ocasiones, si eso de algo sirve. No sabemos a ciencia cierta por qué a pesar de tantas instituciones y organizaciones que se han conformado, esa violencia sigue aumentando y quiénes están coludidos no sólo en la ejecución, sino en la no resolución de los casos. Hay quien dice que es a causa del narcotráfico, que se ha infiltrado en los diversos gobiernos estatales; otros sostienen que son las parejas quienes ejercen violencia por sentirse mal, odiar a su pareja, estar borrachos o expresar su violenta masculinidad misógina y patriarcal. Hasta ahora las violencias siguen aumentando (Monárrez Fragoso et al., 2010).

Todo este escenario tan sombrío es el que ha tocado vivir a las mexicanas que tienen miedo a cada momento al salir a la calle y convertirse en víctimas o por convivir con el agresor dentro del hogar. Las jóvenes feministas han heredado ese miedo y se han agrupado en colectivas para tratar de atajarlo. Además, no sólo esas jóvenes han protestado, también feministas de todas las edades hemos gritado contra esa violencia que enfrentamos.

Como este ensayo tiene por objetivo examinar algunas acciones que las jóvenes mujeres han emprendido contra las violencias en estas dos últimas décadas, hay que mencionar las tensiones y debates que se desarrollan entre las distintas propuestas que esgrimen algunas de las jóvenes y que pelean con las feministas de la segunda ola. No están de acuerdo unas con otras y sus discusiones cada vez son más agrias. Las distintas vertientes de jóvenes colectivas no aceptan el diálogo con el gobierno, ya que éste no las ha tomado en cuenta y no las escucha. Mientras tanto, las otras cabildean y se muestran más cercanas con el poder, incluso algunas de ellas se han convertido en asesoras femócratas, por ejemplo, de la Jefa de Gobierno de la Ciudad de México. Estas actitudes han separado a unas de otras y ello ha dejado un vacío intergeneracional que va a ser difícil de remontar.

\section{"Si tocan a una respondemos todas"}

\section{Los feminicidios: una más de las apropiaciones del patriarcado}

El jueves 10 de junio de 2021 una noticia en el diario La Jornada, firmada por Arturo Sánchez Jiménez, captó mi atención: Según el informe 2021 del Índice de Paz México elaborado por el Instituto para la Economía y la Paz, se menciona que

\begin{abstract}
44 por ciento de las mujeres en México han experimentado violencia en una relación amorosa durante su vida. A diferencia del predominio de las armas de fuego en los homicidios de hombres, la mayoría de los feminicidios se cometen con otros artefactos. Con 13\%, la proporción de víctimas de feminicidio menores de 18 años es mucho mayor que la de sus contrapartes del sexo masculino (Sánchez Jiménez, 2021: 11).
\end{abstract}

Esta nota da cuenta de que las mujeres mexicanas están siendo asesinadas a una tasa de incremento impresionante en números que dan terror. Este fenómeno empezó a datarse desde la década de los 90 y la proporción desde entonces se ha agravado a un ritmo dramático y directamente relacionado tanto con la expansión del neoliberalismo como con el capitalismo salvaje. No digo que antes no hubiera feminicidios, pero no contábamos con la numeralia que hoy estamos encarando. La presión ejercida 
por feministas desde entonces ha incidido en que los gobiernos, a veces, lo consideren un problema que se vincula estrechamente con la crisis de gobernabilidad, seguridad interna y por supuesto el respeto a los derechos humanos de las mujeres (Olivera, 2006: 104).

Frente a la indiferencia y carencia de datos fidedignos, un grupo de mujeres activistas, académicas y políticas se congregó para vigilar la rendición de cuentas (daliaempower.com). Se nombraron "Nosotras tenemos otros datos". Su labor ha probado que la violencia se ha incrementado y una de las causas ha sido por la epidemia de Covid-19 $y$ el confinamiento en los hogares. Afirman que entre enero y marzo de 2021 el número 911 recibió cerca de 17 millones 225,555 llamadas de emergencia, de las cuales $90 \%$ fueron de auxilio. Comparan las cifras con la Encuesta Nacional sobre la Dinámica de las Relaciones en los Hogares (ENDIREH) del Inegi, que en 2016 reportó que $66.1 \%$ de mujeres sufría violencia. En cambio, en 2021 la violencia creció hasta alcanzar $52.3 \%$, el abuso sexual $10.1 \%$, el acoso $16.7 \%$, la violación $8.4 \%$ y la violencia familiar $6.4 \%$. Contrastan sus cifras con los datos que presenta el Secretariado Ejecutivo del Sistema Nacional de Seguridad Pública (SESNSP), el cual toma su información de las fiscalías y procuradurías de las 32 entidades federativas que componen la república. EI SESNSP afirma que de enero a octubre de 2021 el total de delitos presentados ascendió a 1 millón 700,689 y entre ellos el 0.05\% fue de feminicidios y el $1.40 \%$ de homicidios dolosos. Las integrantes de "Nosotras tenemos otros datos" afirman que no se clasifican como feminicidios los que corresponden a los homicidios dolosos. Aseveran que hoy día hay 20 mujeres asesinadas diariamente. ${ }^{6}$

\section{\#Vivas nos queremos}

El Movimiento de Liberación de las Mujeres o también Ilamado Segunda Ola Feminista supuso en los años 60 uno de los logros más

6 https://www.facebook.com/nosotrastenemosotrosdatos/ significativos respecto a la participación de las mujeres en la esfera pública. Este movimiento social pretendía y sigue haciéndolo liberar a las mujeres de los trabajos del hogar y conseguir la igualdad salarial, además del uso libre de la píldora anticonceptiva y el derecho al aborto. Estas exigencias pusieron en jaque a las agendas de las organizaciones políticas de izquierda que se vieron rebasadas por reivindicaciones que no eran tomadas en cuenta.

El feminismo, como teoría y práctica política, implica un planteamiento revolucionario de redefinición del mundo, y con ello no sólo hablamos de relaciones más igualitarias entre hombres y mujeres; cuestionar cómo la política tiene que poner al centro a la persona en toda su complejidad, la importancia mayúscula del tema de los cuidados en un contexto donde el ciudadano ya no puede ser visto como un individuo abstracto (Cerva Cerna, 2020: 3)

A lo largo de su trayectoria este movimiento feminista de la segunda ola mexicana $^{7}$ ha esgrimido como una de sus demandas cardinales erradicar la violencia contra las mujeres. Sus reclamos han girado en torno a la exigencia de cuestionar y dar a conocer esas prácticas de violencia que enfrentan las mujeres; esta forma de abordar dicha violencia empezó como una realidad social y estructural y se ha naturalizado por la gran cantidad de asesinatos de mujeres. Desde entonces no se ha quitado el dedo del renglón acerca de la prevalencia de esa violencia que ahora se define como en "razón de género"8 y que es una forma extre-

7 Considero que los feminismos mexicanos han transitado por varias olas: la primera, que demandó el sufragio y duró hasta 1953; la segunda, de 1970 hasta 1998, y la tercera desde entonces a la fecha.

8 Razón de género es un concepto sociológico que describe las desigualdades históricas que genera la discriminación y que se traduce en relaciones de poder, abuso, misoginia, control, dominación y subordinación de las mujeres. En los feminicidios, estas desigualdades se reflejan en las formas en que las mujeres son asesinadas, en los tipos y expresiones de violencia que se ejercen en sus cuerpos, asi como las personas que atentan con la vida de las mujeres, en que, incluso, se abusa de ámbitos o relaciones de confianza en los 
ma de poder para someter a las mujeres a la violación, violencia doméstica, hostigamiento, acoso y hasta trata, y como dicen Caputi y Russell, se ha convertido en una "política sexual de muerte" (sexual politics of murder). Estas autoras la califican como "la forma más extrema de terrorismo sexista motivado por odio, desprecio, placer o sentido de propiedad sobre una mujer" (Caputi y Russell, 2006: 53-54). Esta violencia se desarrolla de múltiples maneras, pero su expresión más deleznable es el feminicidio, que ha cobrado una incidencia exponencial, ya que "en casi $85 \%$ de las entidades federativas se considera que existe un contexto de violencia feminicida" (Olivares Alonso, 2021: 5). Datos recientes indican que a lo largo del país hoy día se cometen entre 10 y 11 feminicidios diarios. Estos asesinatos dan cuenta de una tecnología de la dominación/ agresión/maltrato/tortura y discriminación hacia las mujeres por el solo hecho de serlo.

Los últimos veinte años dan entrada a lo que podemos considerar como una "tercera ola" feminista que se caracteriza por el "hartazgo de millones de mujeres en el mundo que han reaccionado de manera impresionante frente a la violencia, la opresión y la discriminación" (Varela, 2019: 17). En el caso de los feminismos mexicanos, esa marejada llega acompañada por la toma de conciencia, la rabia e indignación hacia las violencias y la indiferencia de los poderes del Estado. Además, mantienen una diversidad de corrientes teóricas y de activismos diversos, de etnias y de religiones, de sexualidad, de procesos culturales y prácticas políticas. Encontramos colectivas de jóvenes que se autodefinen como radicales, autónomas, anarcofeministas, decoloniales, ecologistas, antiespecistas ciberfeministas, transfeministas, lesbofeministas, hackfeministas y también encontramos blogueras feministas entre otras muchas que proponen distintas narrativas, propuestas y acciones colectivas. Sus formas de lucha se expresan desde la protesta social y tienen su base en las redes sociales, desde donde globalizan

que existe discriminación, como los ámbitos familiar, laboral o docente. sus iniciativas y llaman a las movilizaciones; el papel de internet, de Facebook y de Twitter han sido su modus operandi y su forma de protesta social.

Cada nuevo oleaje feminista entraña prácticas políticas y posicionamientos diversos como se ha mencionado arriba; unas y otras pluralizan sus planteamientos y acuerdan aliarse en común en ciertas coyunturas, como son las violencias que las enfurecen. Están aquellas que usan su cuerpo con contenido político y como territorio de lucha y quienes buscan visibilizar las estructuras sexistas que las oprimen y luchan a través del arte contra la imposición de narrativas androcentristas y empiezan a surgir grupos que rechazan la solemnidad y apuestan por un feminismo lúdico. No obstante, la presencia simbólica feminista, su activismo político y sus prácticas ha mantenido vivo al movimiento en la conciencia colectiva, aunque definirse como feminista siga siendo motivo de violencia, desconfianza, burla y peligro.

Los tres sexenios de este siglo XXI han mostrado que el país ha transitado por una transformación de un partido hegemónico por otro que resultó igual para las mujeres, a quienes no les respetan sus derechos humanos, ni tampoco sus cuerpos y vidas. Para las mujeres el multimencionado cambio aún no ha llegado.

Desde 2006 hasta 2021 el panorama de violencia se incrementó tanto para hombres como para mujeres. La lucha emprendida contra los cárteles de narcotraficantes además de sacar al Ejército a las calles avivó una violencia que hasta la fecha sigue extendiéndose y no se ha controlado. Los feminicidios se han agudizado y han repuntado muchos agravios como el acoso, la violación, la discriminación, el abuso en distintos entornos, los secuestros, las desapariciones forzadas y la trata de mujeres.

Al mismo tiempo en estos años la relación al interior de los feminismos mexicanos se ha complejizado: encontramos feministas llevando a cabo una serie de acciones colectivas; algunas desde los partidos políticos intentando poner en marcha agendas de género; al mismo tiempo han surgi- 
do jóvenas que exigen ser incorporadas al acervo de los derechos básicos, y aquellas que cada vez más se profesionalizan, convirtiéndose en expertas generistas y aquellas que se han transformado en femócratas convencidas que hay que trabajar con las autoridades para incidir en ellas.

Como se ha podido observar, hoy día los feminismos conocen nuevas formas de expresión y de intervención, entre lo que puede considerarse un feminismo institucional que reviste varias formas que van desde los pactos interclasistas, la operación mediante cabildeos o grupos de presión, hasta la creación de secretarías o institutos de las mujeres. Asimismo, encontramos a las jóvenes que quieren quemarlo todo y comenzar desde cero; éstas no obtienen respuestas a sus demandas y sus acciones son consideradas violentas y se trata de reprimirlas a toda costa. "Vale más una piedra que una vida", se nos repite sin cesar. No entienden y nos degradan.

Estas conductas contra las instituciones muestran que los feminismos están viviendo modificaciones en sus dinámicas y estrategias, diversificando la orientación de sus luchas y eso preocupa al poder por el efecto mediático que implica. Han surgido tensiones al interior de los grupos y colectivas que tienen que ver con el rumbo que han tomado las acciones que esgrimen los feminismos y las feministas: el dilema sobre la relación con el Estado se encuentra en la mesa de la discusión y no parece haber diálogo posible. Además, se han agregado demandas por derechos de cuarta generación, como son los económicos y por supuesto los sexuales y reproductivos, que por cierto son los que más resistencia enfrentan por parte no sólo del Estado, sino de sectores de la derecha y de la Iglesia.

Estas colectivas de jóvenes mujeres han resultado muy inventivas y originales en sus prácticas políticas, ya que han creado nuevas tácticas y estrategias, métodos para agitar y protestar frente al poder que las ignora, mientras ellas organizan sus luchas de manera lúdica, artística, performativa y original en sus procederes. Se trata de crear espacios que permitan luchar por la liberación y los cambios, con el objetivo de robustecer y darle solidez al movimiento.

\section{Salgamos a tomar las calles. “\#La revolución será feminista o no será”}

La década de 2010 a 2020 es el momento cuando las mujeres jóvenes aparecen cada vez más en el espacio público. Su movimiento es intergeneracional. Algunas de las jóvenes morras, como ellas se identifican, son herederas de la tradición feminista de los años 70 y 80 y muchas de sus demandas se empatan con las de aquéllas. Si bien las actoras de las colectivas son muy jóvenes han encontrado interlocución con algunas antecesoras. No obstante, sus prácticas discursivas difieren de las predecesoras, y en el caso de la violencia sexual las niñas, adolescentes y jóvenes son las que sufren más y no aceptan formar parte de esos grupos ni quieren interlocución con aquéllas.

Las colectivas andan por todas partes y saben cómo comunicarse entre ellas. Los hashtags acompañan sus eslóganes y cada vez imaginan nuevos. Son muy conscientes de lo que está sucediendo en el país y pugnan por erradicar la violencia y poner un alto a los feminicidios. Son las que enfrentan y luchan de muchas maneras, desde salir a la calle masivamente, manchar y pintarrajear monumentos, usar la música, el baile e improvisar acciones artísticas efímeras para dar cuenta de su rabia e indignación. Toman escuelas y facultades de universidades y centros de estudios para mostrar que en todos lugares existen violencias y las autoridades hacen caso omiso de ellas. "El uso de las redes sociales, así como otras plataformas digitales y tecnológicas han sido fundamentales para la articulación del movimiento feminista actual, sin dejar de lado a los medios de comunicación más tradicionales" (Lau Jaiven y Viera Alcazar, 2020: 148).

El 24 de abril del 2016, marchas feministas contra la violencia machista se desarrollaron en 27 ciudades del país. Conminadas a través de las redes sociales, se llevó a cabo 
la "Primavera violeta", que reunió a miles de mujeres que salieron a las calles a exigir a la sociedad y a las autoridades la visibilización y erradicación de las violencias machistas y justicia por el incremento de feminicidios en el país, sobre todo los miles de casos no resueltos en el Estado de México. La "Primavera violeta" nos recordó que sin importar lo que consiste la llamada perspectiva de género que ha sido incorporada por las instituciones gubernamentales y en algunas legislaciones, las autoridades no la ponen en práctica y puedo añadir que no saben a qué se refiere.

La movilización nacional contra las violencias machistas se llevó a cabo el 24 de abril de 2016 e inició en Ecatepec:

\begin{abstract}
Tras seis horas de recorrido, el contingente de miles de manifestantes llegó al pie del Ángel de la Independencia, de la Ciudad de México (,) para rechazar las diferentes violencias que padecen las mujeres en México diariamente. Entre las exigencias que colectivos de mujeres dieron a conocer, está el cese al favoritismo judicial hacia los hombres en proceso [sic] penales, capacitación en materia de violencia de género en instituciones públicas; oportunidades de empleo y de trabajo dignas y seguras, así como mecanismos para combatir el machismo en el país (Animal Político, 2016).
\end{abstract}

La marcha \#24A logró ser una de las movilizaciones feministas más importantes del país. Al tiempo que la marcha se desarrollaba, coincidía con la etiqueta \#MiPrimerAcoso, que llenaba las redes sociales Facebook y Twitter, donde miles de mexicanas relataron abiertamente la primera vez que sufrieron un acoso sexual (Paullier, 2016).

Al año siguiente, un feminicidio estremeció a las estudiantas universitarias: el de la joven Lesvy Berlín Osorio en mayo de 2017, en el campus de la Universidad Nacional Autónoma de México (UNAM), ${ }^{9}$ lo cual trajo la urgente necesidad de voltear a ver los espa-

9 Hasta 2019, después de la incesante lucha de Araceli Osorio, madre de Lesvy, con apoyo de algunos grupos feministas, ha sido posible señalar al exnovio de la joven como responsable del feminicidio efectuado, siendo consignado a prisión por 45 años. cios educativos, las escuelas (consideradas aparentemente "espacios seguros") como un lugar que necesita reconocer la violencia machista que se produce y se sostiene en las prácticas cotidianas. Este feminicidio, que en un principio se clasificó como homicidio doloso, desataría una serie de exigencias en torno a la construcción de protocolos y unidades contra la violencia en las instituciones de educación superior. La madre de Lesvy, Araceli Osorio, luchó junto con abogadas feministas durante año y medio para que el asesinato de su hija fuera catalogado e investigado como feminicidio y para que se castigase con toda la fuerza de la ley a Jorge Luis, su asesino. ${ }^{10}$

Las denuncias públicas, aunadas al uso de las redes sociales, ya se dejaban ver por parte de las jóvenes desde 2017. Así, la creación de grupos digitales para señalar al macho que ha acosado u hostigado en distintos espacios sociales se hace presente como una estrategia autónoma y colectiva por parte de las feministas para cuidarse entre ellas. Así también, las protestas y notificaciones que se hicieron sobre las violaciones y acosos en el transporte público provocaron que las autoridades e instancias públicas se dieran a la tarea de atender los casos de esas víctimas. Una de las estrategias que más Ilamó la atención fue la llamada "Vive Segura", que consistió en la entrega de silbatos en el transporte público para que las mujeres lo utilizaran cuando fueran agredidas (Hernández, 2017). Con esta acción se pretendía que las capitalinas estuvieran alertas. Esta lamentable idea, que dio resultado en el Reino Unido, provocó la ira de varias organizaciones que no estuvieron de acuerdo con estas iniciativas que no resolvían nada y sólo parecían una burla frente a lo que estaba pasando. Por su parte, las estudiantes universitarias aprovecharon la coyuntura para denunciar el acoso dentro de las aulas. Alumnas de la unidad Xochimilco de la Universidad Autónoma Metropoli-

10 El grupo "Nosotras tenemos otros datos" considera que los ministerios públicos y los jueces clasifican esos asesinatos de mujeres como homicidios dolosos para bajar el número de feminicidios. 
tana elaboraron un muro donde exhibieron con nombre y apellido a los profesores que las acosaban. En otros espacios, los tendederos fueron la manera de exhibir a los académicos acosadores, violadores y abusadores. Pero, además, las estudiantas de la UNAM interrumpieron actividades y al no obtener respuestas tomaron algunos edificios de facultades y Colegios de Ciencias y Humanidades denunciando igualmente a los acosadores.

\section{\#PrimeroLasMujeresLuegoLasParedes}

Otro acontecimiento que cimbró a la capital y bautizó como vándalas a las feministas fue una acción que desde mi punto de vista debió ser lúdica y terminó enojando a las feministas y a las autoridades que no entendieron el significado de dicho acto. El 12 de agosto del 2019 apareció "la diamantina violeta”, que se conoce como la brillantinada. Durante una manifestación por hechos de violencia de parte de la policía, las mujeres se presentaron en la puerta de la Secretaría de Seguridad Ciudadana y posteriormente en la Procuraduría General de Justicia (PGJ) para denunciar \#NoMeCuidanMeViolan, con relación al caso de una joven que aparentemente había sido violada por cuatro policías en la capital. Mujeres de todas las edades dejaron oír icónicas consignas como: “\#cquién nos cuida de la policía?” y "\#cualquier violencia sexual por parte de un agente es tortura”. El secretario de Seguridad Ciudadana de la Ciudad de México, Jesús Orta, tras percatarse de la protesta, se presentó ante los medios de comunicación. Al ser entrevistado, afirmó que dos policías implicados en uno de los casos que motivaban la manifestación aún permanecían en servicio. La reacción de irritación y enfado de las manifestantes no se hizo esperar y la respuesta fue lanzarle diamantina morada sobre el cabello y el rostro.

Esa acción que podría haberse considerado una broma y no una provocación como se le denominó se convirtió en un acto de violencia de parte de las mujeres que destruyeron vidrios y grafitearon monumentos.
El 16 de agosto, cuatro días después, grupos feministas llevaron a cabo una marcha cuya protagonista principal fue el símbolo del glitter y la diamantina. Esta marcha causó estruendo y emoción, pues dejó en claro que "exigir justicia no es provocación" y en respuesta a la inseguridad y violencia policial las manifestantes volvieron a destruir todo a su paso. Estos actos fueron catalogados como violentos por algunos sectores sociales y el estigma de las feministas como "radicales" y "vándalas" se ha extendido hasta hoy. Hay que mencionar que cuando la violencia la llevan a cabo los hombres, se le considera normal, así son. Pero si lo hacen las mujeres, ellas pierden su feminidad y ello no debiera ser, ya que se malogra el orden de género.

El gobierno de la Ciudad de México solicitó borrar las pintas del Ángel de la Independencia y un colectivo conformado por un grupo multidisciplinario de mujeres especialistas en restauración, conservación del patrimonio cultural, que tenían que llevar a cabo esa misión, se negaron a hacerlo y así nació "Restauradoras con Glitter", que argumentó "que dichas pintas representan el clamor de justicia y de visibilizar las agresiones, acoso, violaciones y feminicidios a los que día a día se enfrenta una mujer en México" (Santamaría, 2019).

El 8 de marzo de 2020 más de un millón de mujeres de todas las clases sociales y edades vestidas de morado marcharon por las calles de la capital para demandar el cese de las violencias machistas. Si bien hubo provocaciones no fueron de parte de las mujeres. Ellas sólo grafitearon los monumentos y rompieron vidrios.

Otro suceso que al principio no fue muy bien recibido por la opinión pública fue la toma de las oficinas de la Comisión Nacional de Derechos Humanos en la calle de Cuba número 60. La falta de atención hacia los feminicidios y violaciones empujó a varias mujeres y jóvenes a ocupar dicha sede en septiembre de 2020. Cambiaron el cartel, pusieron cruces rosas y nombraron al edificio como "Casa de Refugio". Al interior del 
inmueble se imparten cursos y se realizan actividades de todo tipo, por ejemplo, una "mercadita", cuyas ventas les ha permitido mantenerse. Continúan todavía ahí y ya no les hacen caso (Galván, 2021).

El 8 de marzo de 2021, a pesar de la pandemia y sus consecuencias, muchas mujeres salieron de nuevo a manifestarse y fue el colmo: el gobierno envolvió con plásticos los monumentos por donde iban a pasar las feministas para que no los pintaran, mientras que la Catedral Metropolitana y el Palacio Nacional fueron rodeados con vallas, que amanecieron con los nombres de las asesinadas por feminicidios. Esta iniciativa fue magnífica, pero la respuesta no. Se las acosó, se les arrojó gas pimienta e incluso se las golpeó. Todos estos hechos por supuesto fueron negados por las autoridades:

Mujeres encapuchadas escalaron el 25 de septiembre por el pedestal, ubicado en una rotonda del céntrico Paseo de la Reforma, para instalar y desvelar la figura de una mujer con el puño en alto. En el comunicado, las activistas declararon que el espacio está dedicado a las mujeres que buscan a sus familiares desaparecidos, a las madres de víctimas de feminicidios y a sus hijas, a las defensoras del territorio, a las afromexicanas, a las indígenas y a "todas las mujeres que con sus luchas han construido nuestra historia" (Agencia EFE, 2021).

Como se ha podido apreciar, la violencia que se ha exacerbado contra las mujeres en razón de género se ha convertido en una problemática imparable que se manifiesta a través de la violencia familiar, las violaciones, los feminicidios e incluso la violencia de las y los policías en tiempos de la Covid-19. Por eso insisto que la violencia contra las mujeres se ha convertido en una pandemia dentro de otra pandemia.

Por último, hay que subrayar que el gobierno federal y las entidades que lo conforman se han convertido en cómplices de lo que sucede, ya que no han dado resultados y culpan a las víctimas, lo cual ha servido para agrandar la rabia y el coraje de las feministas. La contingencia sanitaria derivada de la crisis por coronavirus ha disparado el número de feminicidios en el país. Tan solo en el primer semestre de 2020 se contabilizaron 1844 homicidios de mujeres, de acuerdo con cifras del Instituto Nacional de Estadística y Geografía (Inegi).

Para terminar, quiero cerrar con una frase de Sara Ahmed de su libro La promesa de la felicidad:

Por el solo hecho de autoproclamarse feministas, de las feministas se piensa que vienen a destruir algo que los demás consideran no solo bueno, sino la causa de la felicidad. La feminista aguafiesta le "arruina" la felicidad a los demás; lo hace porque se rehúsa a convenir, acordar o congregarse en torno a la felicidad (2019).

\section{Fuentes consultadas}

Agencia EFE (2021), "Feministas intervienen (otra vez) glorieta de Colón para que sea dedicada a luchas de mujeres", El Financiero, 3 de octubre, Ciudad de México, Grupo Multimedia Lauman, CDMX, https://cutt.Iy/IUEGzyj, 29 de diciembre de 2021.

Ahmed, Sara (2019), La promesa de la felicidad, Buenos Aires, Caja Negra.

Borzacchielo, Emanuela (2020), "Re-existir: prácticas para cuidar las vidas. Entre academia y periodismo", en Cathy Fourez y Michèle Guillemont-Estela (dir.), Arts et journalisme: Une rencontre à l'épreuve du réel, Bruselas, Peter Lang, S.A./Éditions scientifiques internationals, pp. 225-238.

Borzacchiello, Emanuela y Galanti, Valeria (2015), "Palabras, escenarios e imágenes: comunicar la violencia de género", GénEros. Revista de investigación y divulgación sobre los estudios de género, núm. 16, Época 2, Año 21, Colima, Universidad de Colima, pp. 145-164.

Caputi, Jane y Russell, Diana E.H. (2006), “Feminicidio: Sexismo terrorista contra las mujeres", en Diana E.H. Russell y Jil Radford (eds.), Feminicidio. La política del asesina- 
to de las mujeres, Ciudad de México, CElICH/UNAM/Cámara de Diputados.

CEDAW (Convención sobre la Eliminación de Todas las Formas de Discriminación contra las Mujeres y su protocolo Facultativo) (1979), Protocolo Facultativo de la Convención sobre la eliminación de todas las formas de discriminación contra la mujer, Ciudad de México, SRE/PNUD/UNIFEM.

Cerva Cerna, Daniela (2020), "La protesta feminista en México. La misoginia en el discurso institucional y en las redes sociodigitales", Revista Mexicana de Ciencias Políticas y Sociales, Ciudad de México, Universidad Nacional Autónoma de México, Nueva Época, Año LXV, núm. 240, pp. 177-205.

DOF (Diario Oficial de la Federación) (2015), "Ley General de Acceso de las Mujeres a una Vida Libre de Violencia", 17 de diciembre, Ciudad de México, Cámara de Diputados, https://cutt.ly/uUEsOmB, 25 de noviembre de 2021.

Galván, Melissa (2021), "Un año de la toma de la CNDH: resistencia, refugio y economía feminista", Expansión Política, 2 de octubre, Ciudad de México, Grupo Expansión, Sociedad, https://cutt.ly/ UUED5pU, 25 noviembre 2021.

González Rodríguez, Sergio (2002), Huesos en el desierto, Barcelona, Editorial Anagrama.

Haraway, Donna (1991), "A Cyborg Manifesto: Science, Technology, and Socialist Feminism in the Late Twentieth Century", en Simians, Cyborgs and Women: The Reinvention of Nature, Nueva York, Routledge, https://cutt.ly/eUECaDX, 28 de diciembre de 2021.

Hernández, Sandra (2017), "Silbato antiacoso ¿eficaz?", El Universal, 13 de agosto, Ciudad de México, El Universal, Metrópoli, https://cutt.ly/OUECvRt, 29 de diciembre de 2021.

Inegi (Instituto Nacional de Geografía y Estadística) (2016), "Encuesta Nacional sobre la Dinámica de las Relaciones en los Hogares (ENDIREH) 2016", Ciudad de
México, Inegi, https://cutt.ly/vUEL6jt, 29 de diciembre de 2021.

Lagarde, Marcela (2012), El feminismo en mi vida. Hitos, claves y topías, Ciudad de México, Gobierno de la Ciudad de México/Instituto de las Mujeres del Distrito Federal.

Lau Jaiven Ana y Viera Alcazar, Merarit (2020), "Feminismos en México: Diálogos intergeneracionales y prácticas políticas contra la violencia hacia las mujeres", en Mónica Cejas, Liliana López Levi y Angélica Rosas Huerta, Logros, retos y contradicciones de la 4T, Ciudad de México, UAM-Xochimilco.

Lau Jaiven, Ana (2002), "El nuevo movimiento feminista mexicano a fines del milenio", en Eli Bartra, Anna Fernández Poncella y Ana Lau Jaiven, Feminismo en México, ayer y hoy, col. Molinos de Viento, núm. 130, Ciudad de México, Universidad Autónoma Metropolitana.

Millett, Kate (1975), Política sexual, Ciudad de México, trad. de Ana María Bravo García, Aguilar.

Monárrez Fragoso, Julia; Cervera Gómez, Luis Ernesto y Fuentes Flores, César M. (2010), Violencia contra las mujeres e inseguridad ciudadana en Ciudad Juárez, Ciudad de_México, Miguel Ángel Porrúa/El Colegio de la Frontera Norte.

Monárrez Fragoso, Julia (2009), Trama de una injusticia. Feminicidio sexual sistémico en Ciudad Juárez, Ciudad de México, El Colegio de la Frontera Norte/ Miguel Ángel Porrúa.

Olivares Alonso, Emir (2021), "CNDH: en México, siete feminicidios cada día", $L a$ Jornada, 13 de noviembre, Ciudad de México, Demos, Política, https://cutt. ly/zUEBovU, 28 de diciembre de 2021.

Olivera, Mercedes (2006), "Violencia Feminicida. Violence against Women and Mexico Structural Crisis", en Rosa-Linda Fregoso y Cynthia Bejarano (eds.), Terrorizing Women: Feminicide in the Americas, Durham, Duke University Press, doi: https://doi. org/10.1215/9780822392644-003 
Paullier, Juan (2016), "\#MiPrimerAcoso, la creadora del hashtag que sacudió internet y la importancia de que las mujeres no callen", BBC Mundo, 25 de abril, Ciudad de México, British Broadcasting Corporation, <https://cutt.ly/ YUETqOR>, 29 de diciembre de 2021.

Rovira-Sancho, Guiomar (2013), "Activismo mediático y criminalización de la protesta: medios y movimientos sociales en México", Convergencia. Revista de Ciencias Sociales, 20 (61), Toluca, Universidad Autónoma del Estado de México, pp. 35-60, <https://cutt.ly/xUEOdfm>, 29 de diciembre de 2021.

Sagot Rodríguez, Montserrat (2021), "Voz experta: la violencia contra las mujeres en un mundo en emergencia", San José, Universidad de Costa Rica, <https://cutt.ly/KU2YOGi>, 22 de noviembre de 2021.

Sagot Rodríguez, Montserrat (2013), "El femicidio como necropolítica en Centroamérica", Revista Labrys, études féministes/ estudos feministas, <https:// cutt.Iy/yU2IV7n>, 7 de enero de 2022.

Salas, Kenia (2020), "Feminicidio en contexto: Cultura y poder en la lente de la prensa del Estado de México", en Mónica Inés Cejas (coord.), Feminismo, cultura y política. El contexto como acertijo, Ciudad de México, UAM-X/Itaca.

Sánchez Jiménez, Arturo (2021), "Subió 84.12\% la tasa de homicidios en México desde 2015: informe", La Jornada, 10 de junio, Ciudad de México, Demos, Política, p. 11.

Santamaría, Verónica (2019), "Restauradoras con Glitter: las pintas en el Ángel, la memoria de un grito contra la violencia hacia las mujeres", Animal Político, 25 de agosto, Ciudad de México, <https://cutt. ly/ZUESO5N>, 28 de diciembre de 2021.

Secretaría de Relaciones Exteriores (2008), Convención Interamericana para Prevenir, Sancionar y Erradicar la Violencia contra la Mujer, "Convención de Belém do Pará" y su Estatuto de Mecanismo y Seguimiento, Ciudad de México, Secretaría de Relaciones Exteriores/UNIFEM/PNUD.
Segato, Rita Laura (2007), “¿Qué es el feminicidio? Notas para un debate emergente", en Marisa Belausteguigoitia y Lucía Melgar (coords.) Fronteras, violencia, justicia: nuevos discursos, Ciudad de México, PUEG/UNIFEM/UNAM.

Varela, Nuria (2019), Feminismo para principiantes, Ciudad de México, Penguin Random House.

Viveros Vigoya, Mara (2016), "La interseccionalidad: una aproximación situada a la dominación", Debate Feminista, vol. 52, Ciudad de México, UNAM-Centro de Investigaciones y Estudios de Género, pp.1-17, doi: https://doi.org/10.1016/j.df.2016.09.005

Recibido: 6 de octubre de 2021. Aceptado: 26 de noviembre de 2021. Publicado: 24 de enero de 2022.

\section{Ana Lau Jaiven}

Es doctora en Historia por la Universidad Iberoamericana. Actualmente es profesora investigadora en la Universidad Autónoma Metropolitana, Unidad Xochimilco, en el Departamento de Política y Cultura. Imparte docencia en la Maestría en Estudios de la Mujer y en el Doctorado en Estudios Feministas. Es miembro del Sistema Nacional de Investigadores, nivel $1, y$ es investigadora con perfil PRODEP (Programa para el Desarrollo Profesional Docente). Sus líneas de investigación son: historia de los feminismos mexicanos, del sufragio femenino y de los grupos organizados de mujeres a lo largo del siglo XX. Entre sus más recientes publicaciones destacan, como co-coordinadora: Diccionario enciclopédico del feminismo $y$ los estudios de género en México, Ciudad de México, Cieg/UNAM (2019) y Rupturas y continuidades. Historia y Biografías de $\mathrm{Mu}$ jeres, Ciudad de México, UAM-Xochimilco (2018). 